\section{Case Reports in Neurology}

Case Rep Neurol 2021;13:119-122

DOI: 10.1159/000512403

Published online: February 16, 2021
(C) 2021 The Author(s)

Published by S. OP OPEN www.karger.com/crn

This article is licensed under the Creative Commons Attribution-NonCommercial 4.0 International License (CC BY-NC) (http://www.karger.com/Services/OpenAccessLicense). Usage and distribution for commercial purposes requires written permission.

\title{
Sudden Bilateral Deafness in a Patient with Transient Ischemic Attack: A Case Report
}

\author{
Caroline Ellinore Pihl Christina Fredsby Back Helle Klingenberg Iversen \\ Faisal Mohammad Amin \\ Department of Neurology, Rigshospitalet Glostrup, University of Copenhagen, \\ Copenhagen, Denmark
}

\section{Keywords}

Sudden deafness - Bilateral hearing loss - Acute deafness - Acute hearing loss - Stroke Transient ischemic attack

\begin{abstract}
Sudden-onset bilateral cortical deafness is a very rare symptom of stroke, but must be recognized as stroke, as it is a treatable condition, and the treatment is highly time dependent. We report a 53-year-old man with an acute onset of complete bilateral hearing loss that gradually improved spontaneously over $4 \mathrm{~h}$. The hearing loss was explained by an infarction visualized on magnetic resonance imaging, which showed a subacute temporoparietal ischemic lesion in the left cerebral hemisphere involving the insular cortex and an older infarction in the right temporoparietal region. The location of these kinds of lesions may typically not cause motor deficits, but sensory and cognitive (e.g., aphasia) symptoms, which can be challenging to recognize in a suddenly deaf patient. Taking the possible differential diagnoses into account, immediate stroke workup should always be prioritized in patients with sudden bilateral deafness, as acute revascularizing treatment is possible.




\section{Case Reports in Neurology}

Pihl et al.: Sudden Bilateral Deafness in a Patient with Transient Ischemic Attack: A Case Report

\section{Introduction}

Sudden sensorineural hearing loss in the adult population is usually unilateral and idiopathic [1]. Bilateral sudden deafness is extremely rare and is most often associated with systemic diseases, such as toxicity, infection, autoimmune or neoplastic conditions, and vascular events [2]. The vascular etiology includes vasospasms after subarachnoid hemorrhage [3], intracerebral hemorrhage [4], and ischemic infarctions [5]. Most often, patients have unilateral damage in the primary auditory cortex and later get a vascular lesion on the contralateral side causing bilateral deafness. Here, we present a patient with a transient complete bilateral hearing loss.

\section{Case Report}

A 53-year-old man with a history of arterial hypertension, hypercholesterolemia, chronic heart failure, cigarette smoking, and ischemic stroke with known sequelae, including reduced sensation in the left-sided extremities and mild dysarthria, presented with a complete bilateral hearing loss in May 2018. The patient was watching TV and could suddenly not hear anything, which improved gradually over $4 \mathrm{~h}$. According to his friend, there was also a discrete speech problem, which was not further described. The patient was seen in the emergency room (ER) on the same day (by an internal medicine resident), where nothing abnormal was noted and the patient was discharged. The patient was referred to and seen in the neurological department 2 days later, where the neurological examination revealed slightly reduced hearing on the left side as well as reduced sensation for touch and pain on the left side. No other abnormal neurological findings were reported. An ENT specialist was consulted but did not find it necessary to see the patient. Blood samples (including infection, kidney, liver and lipid status, and glucose and TSH) were unremarkable except for leucocytes of $9.8 \times 10^{9} \mathrm{~L}^{-1}$. The patient had no fever or other signs of infection. Magnetic resonance imaging (MRI) showed a subacute temporoparietal infarct on the left side involving the insular cortex and an older infarct in the right temporoparietal region as shown in Figure 1. The patient underwent routine stroke workup, including ultrasound of the carotid arteries, electrocardiography, telemetry, blood cholesterol and HbA1c, and blood pressure. Moreover, MRI of the heart was performed, which revealed a big aneurysm and an old mural thrombus in the left ventricle. The patient had no complaints at the follow-up visit in the stroke outpatient clinic after 3 months.

\section{Discussion}

Hearing depends on normal function of the peripheral and central auditory pathways. Auditory stimuli from each ear end in both sides of the brain cortex as shown in Figure 2. Thus, unilateral hearing loss cannot be caused by a single cortical lesion, and bilateral cortical deafness requires bilateral cortical damage. As strokes (ischemic or hemorrhagic) almost never cause acute bilateral symmetrical lesions, a vascular genesis of acute bilateral sudden deafness may typically not be suspected as the tentative diagnosis. In the present case, the patient was seen in the ER but was discharged without further examination as the hearing loss had recovered. Retrospectively, the most optimal procedure for this patient would have been an acute referral to a complete stroke workup. Our patient also had a speech problem, which was

\section{Karger'=}




\section{Case Reports in Neurology}

Case Rep Neurol 2021;13:119-122

DOI: $10.1159 / 000512403$

(c) 2021 The Author(s). Published by S. Karger AG, Basel www.karger.com/crn

Pihl et al.: Sudden Bilateral Deafness in a Patient with Transient Ischemic Attack: A Case Report

not mentioned on the initial ER contact, as it was related to communicative impairment because of the hearing loss. Deduced from the MRI findings, the patient has most likely had aphasia, which can be challenging to further categorize in a completely deaf patient. Lesions in the temporoparietal area do not typically cause motor symptoms and are thus difficult to recognize by nonstroke specialists. Toxic, infectious, autoimmune, paraneoplastic, or infectious pathogeneses are differentials in patients with sudden bilateral hearing loss, but in none of these conditions spontaneous rapid complete recovery may be expected. Moreover, in such conditions, other signs or symptoms, such as fever, headache, weight loss, etc., prior to the hearing loss would also be evident. None of these were present in our patient, but on the other hand, he had a history of cerebrovascular disease. Even if a patient does not have apparent cerebrovascular risk factors, immediate stroke workup should be considered in all patients with sudden onset of bilateral deafness, because it is possible to treat the patient with intravenous thrombolysis in case of stroke. If the hearing loss resolves spontaneously within $24 \mathrm{~h}$, it is highly likely due to a transient ischemic attack. Eventually, if stroke is excluded, further workup for other differentials must be carried out subsequently.

\section{Statement of Ethics}

None of the authors have ethical conflicts to disclose. The patient has given written informed consent to publish his case and images.

\section{Conflict of Interest Statement}

F.M.A. has received personal fees for lecturing/advisory board from Novartis, TEVA, and Eli Lilly.

H.K.I. has received personal fees for lecturing/advisory board from Boehringer Ingelheim, Bayer, BMS, and Pfizer.

C.F.B. has received personal fees for lecturing for Boehringer Ingelheim.

\section{Founding Sources}

There was no founding.

\section{Author Contributions}

C.E.P.: writing and editing. F.M.A., C.F.B., and H.K.I.: review and editing.

\section{References}

1 Fetterman BL, Luxford WM, Saunders JE. Sudden bilateral sensorineural hearing loss. Laryngoscope. 1996 Nov;106(11):1347-50.

2 Sara SA, Teh BM, Friedland P. Bilateral sudden sensorineural hearing loss: review. J Laryngol Otol. 2014 Jan;128(S1 Suppl 1):S8-15.

\section{Karger'=}




\section{Case Reports in Neurology}

\begin{tabular}{l|l}
\hline Case Rep Neurol 2021:13:119-122 \\
\hline DOI: 10.1159/000512403 & $\begin{array}{l}\text { @ 2021 The Author(s). Published by S. Karger AG, Basel } \\
\text { www.karger.com/crn }\end{array}$ \\
\hline
\end{tabular}

Pihl et al.: Sudden Bilateral Deafness in a Patient with Transient Ischemic Attack: A Case Report

3 Ramdasi R, Chagla A, Mahore A. Vasospasm causing reversible cortical deafness in subarachnoid hemorrhage. Neurol India. 2014 Jul-Aug;62(4):469-70.

4 Brody RM, Nicholas BD, Wolf MJ, Marcinkevich PB, Artz GJ. Cortical deafness: a case report and review of the literature. Otol Neurotol. 2013 Sep;34(7):1226-9.

5 Narayanan S, Majeed KA, Subramaniam G, Narayanan A, Navaf KM. A Case of Cortical Deafness due to Bilateral Heschl Gyrus Infarct. Case Rep Med. 2017;2017:6816748.
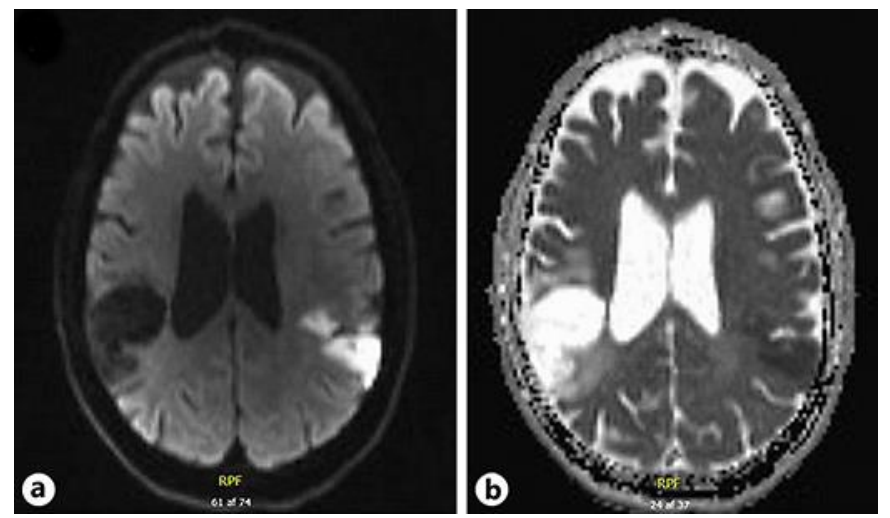

Fig. 1. Diffusion-weighted imaging (DWI) (a) and apparent diffusion coefficient (ADC) (b) sequences obtained by MRI are shown. The left-sided hyperintense area on the DWI and the corresponding hypodense area on the ADC represent subacute ischemic infarction, while the right-sided hypodense area on the DWI and the corresponding hyperintense area on the ADC represent the older ischemic infarction.

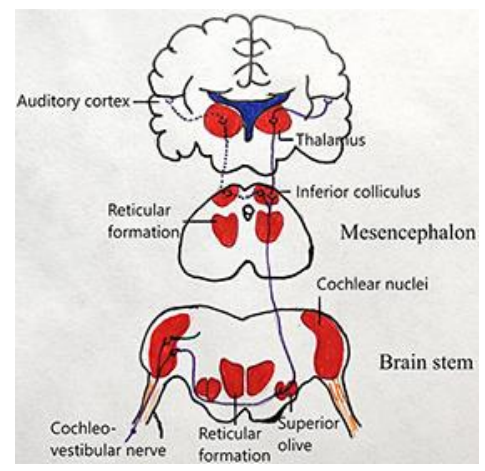

Fig. 2. Nerve fibers from the cochlea end in the brainstem. Some of the nerve fibers project to the ipsilateral superior olivary nucleus and some of the fibers decussate to the contralateral superior olivary complex. Thereafter, the majority of the fibers travel ipsilaterally to the inferior colliculus and the rest to the contralateral inferior colliculus. From the ipsilateral inferior colliculus, the nerve fibers project to the medial geniculate nucleus in the thalamus and finally to the primary auditory cortex.

\section{Karger'}

